\title{
16. Governments Can Deliver: Better Practice in Project and Program Delivery
}

\author{
Ian Glenday, Executive Director, Office of Government \\ Commerce, London
}

\section{Synopsis}

The concept of independent peer reviews leading to improved benefits from major projects and programs is established by some leading enterprises. The British Government's Office of Government Commerce (OGC) have taken this concept and delivered it for nearly 2000 major reviews in British Government. Significant performance improvement has been delivered together with $£ 3$ billion savings.

This chapter examines the strategy for OGC Gateway Brand management, the lessons learnt from the large-scale roll out and the plans for the next phase.

The conclusion is that Governments can improve delivery of policy using this strategy provided robust political and senior official support is established.

\section{Genesis of the OGC Best Practice}

The Office of Government Commerce is the British Government Agency responsible for UK best practice in procurement and project and program management. When it was set up in 2000 it had to decide upon its priorities in the project management area. OGC made a fundamental decision early on to stop work on an already extensive library of project management best practices. Rather OGC wanted to work on how to move these existing best practices to the level it wanted to influence, that of the senior leaders of projects, the senior civil servants and Ministers, to help them understand their role in their projects and policies. OGC chose one service initially, with which it felt it could succeed at that level. That was the service of Independent Peer Reviews of projects by practitioners. This has been very successfully applied by the best of private sector and OGC wanted to translate it into a Brand which became a product and service, free at the point of delivery for Ministers and senior civil servants who were trying to run projects. A big challenge of course was communicating with these clients without any trace of techno gabble that was frightening to them and would have meant the material would have been blindsided immediately. Not because OGC didn't want a professional body of knowledge, but because it wasn't going to help with the selected audience. OGC has been highly successful, 
learnt a lot on the way, and had a lot of fun and excitement in making it work. It is exciting to note that, in Australia, both the Federal and the Victorian state governments decided to proceed on a similar basis. We have applied the service to IT Projects, construction and defence projects all over the UK. The early projects generated success stories which were remembered and used in OGC marketing of the Brand.

\section{Establishing the Brand}

OGC helped turn things around: 'it wasn't rocket science'. For example OGC Gateway helped turn around the Commonwealth Games in Manchester. The Stadiums were relatively straightforward at Manchester, but the project was not doing a terribly good job on getting the roads, rails and security links built on time. These tended to be in silos. It was easy for an independent team to suggest the need to think about these other things in an integrated manner. It was not about what concrete the stadium was made of, it was about whether or not anybody could even get out of the stadium. It is easy to fix when somebody comes in who has done it before, has been there before. Similarly, the UK has had helicopter projects without pilots when somebody forgot to train the pilots. These sorts of things do happen. But things like the Commonwealth Games became a medal on OGC's chest to say 'we' ve done something that really helped'. It is important when running out this sort of campaign not to be ashamed of the publicity involved in saying, 'hey, we do help'. So OGC were successful and said so.

\section{How to Measure Success}

So how would we measure success? Firstly by the large number of volunteer projects that came forward, totalling nearly 2,000. This is a phenomenal number. This suggests that OGC's reputation is high and the reputation is high because of who turns up, to do the Reviews. Teams include very senior civil servants that turn up to review other department's projects. They are not Review Team Leaders, they have a different contribution to make, mainly in the policy deliverability area. However, as part of a balanced team, they are valuable. This is very different to a less experienced person turning up. Ministers are now always interviewed on their projects by the review team and they have been very supportive and very helpful. We are now achieving a 6.5 per cent a year delivery improvement. Whilst we wish it was 100 per cent, there is nothing else that we are doing in Britain which is remotely providing 6.5 per cent across our big portfolio. In value terms the British Government gains 150 times more value out of this than it costs to run the Brand. It costs us five million pounds a year to run it and we make $£ 1$ Billion VFM savings every year. We make a lot of savings out of it but it is not why we do it. We do it because it is a better deal 
for the taxpayer in getting the benefits of projects. Nobody really questions the cash anymore, it is more about the benefits.

\section{The Other Benefits of OGC Gateway}

These sorts of initiatives have very surprising outcomes. One was that OGC learnt so many lessons from the reviews, that The British Government had to put into place a major initiative to set up project management Centres of Excellence (COE's) to embed those lessons in their own departments. The COE's take the lessons, and embed them up front in the next generation of projects, so that if a mistake happens it happens once but it will not happen too many times. So excellence became fallout. Rather fascinating fallout was that all senior civil servants are now required to do Gateway Review training and it is a career expectation to turn up to do Gateway Reviews. These reviews are now the project management training of choice for senior civil servants. So England has nearly 4,000 people now who, because they have been trained as review team members and have turned up on reviews, do their day job quite differently. That is a tremendous outcome, so we managed to get some short term outcomes, some medium term outcomes with the service of excellence and these terrific long term reskilling outcomes. And we have now built that in to the civil service standard career progression criteria. But it has taken five years to get to that happy state. So why did we succeed and how does it help other people?

\section{Why did The British Government Succeed?}

The UK had a clear business case for action. Politicians and the top of the civil service had had enough of failure to deliver. Therefore we did not have to generate enthusiasm. On the other hand OGC didn't have carte blanche. OGC said it could help, but we had to deliver something quickly otherwise support would have evaporated. We were very conscious when we put the program into action that we had to deliver the first set of results within six months. And we did so. So OGC didn't get a blank cheque, it got a blank cheque for a few months to prove a concept which helped make alliances successful. We had the right people involved, we had the head of the civil service literally on the phone every week asking, 'what's going on next?'. Politically, we had our Cabinet minister, the Chief Secretary of the Treasury, Chancellor Brown's deputy, involved in pushing the concept. So we had political support, we had the top official support. Next, we did not delegate this activity of getting the Gateway program underway to a low level. We ran it at a senior level, senior practitioners wrote the procedures as well as getting the reviews done. That was important. The productivity gain was enormous and we spoke the management language of the people we had to communicate with. Not to delegate too far would be a lesson. Of course we did have an important thing, the right structures, to stick with us long term. This was not a short-term program. We made mistakes, learnt, and 
adjusted direction. The board that runs this program, the Office of Government Commerce Supervisory Board is chaired by a Cabinet Minister, and has eight Permanent Secretaries. They lived with OGC and this process for all the meetings and took commitments as to what they were going to do next. It is a very good structure. So we had all the building blocks but we still had to produce a product that mattered. So what about the products?

\section{The Products}

The OGC Gateway product was the first trademarked product, and that's led to other services. The purpose of a product or service is that it is absolutely repeatable, if you have to do it one thousand times the quality will be consistent a thousand times. We could not invent it each time we did it because the UK is a very large-scale business, We had to have something good, repeatable and high quality. We were pursuing a very simple concept. We said there is a life cycle of a project or a procurement which starts with a strategic assessment, moves through a business case, then you choose a contractor from a long list, you check it is ready for service and you get some benefits, pretty easily. We chose six stages as the stages at which an independent review team would look at the project, during its life cycle (Fig. 1). The process emphasises early intervention. The opportunity to improve a project starts when the project begins, it is almost hopeless half way through to try to rescue it.

\section{Figure 1}

\section{Opportunity to Influence Project Outcome}

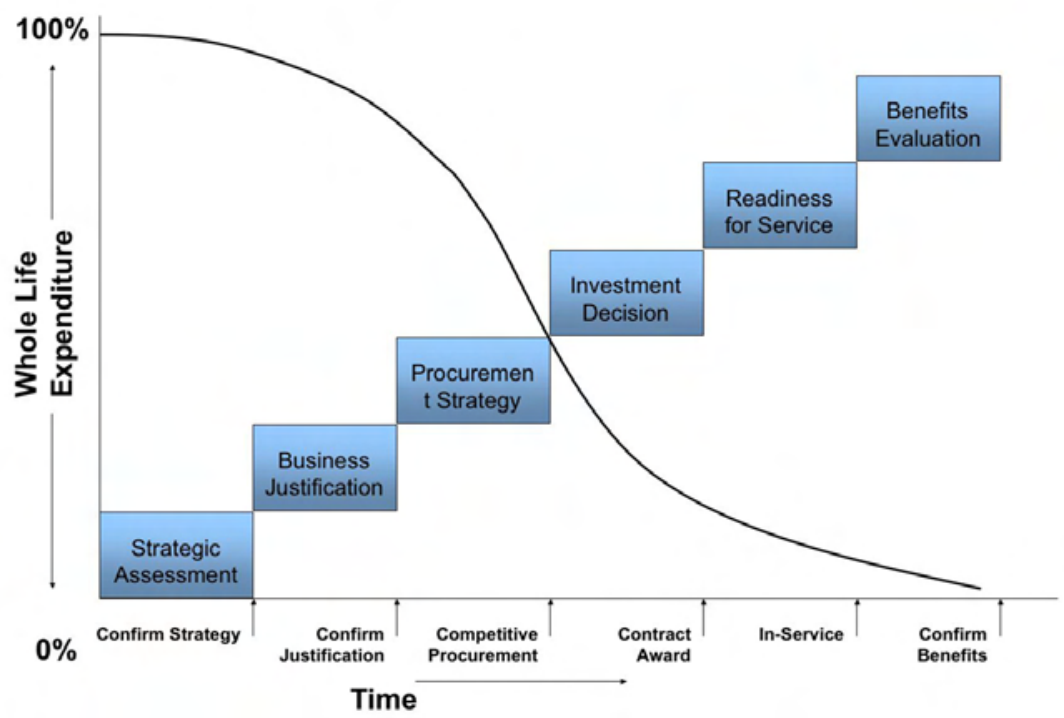


The issue was 'how does one use this as a discipline that is encouraging for the top of the office and for a Minister or anybody else?'. One of the most interesting outcomes of this process when we first used it was the project team sitting down and saying, 'well, actually I thought we were just about to start this project up'. And somebody else would say, 'no actually I have not seen a business case yet'. And somebody else would say, 'I think we'll let the contract tomorrow' and somebody else would say, 'well, actually we have not even agreed a business case or a short list of contractors'. The ability of this sort of diagram and the checklist that goes with it to tell a wide spread number of stakeholders where they actually are was a big win early on. So, using it as a route map just by itself proved very interesting. And then each of these stages had about ten criteria that helped people decide where they should be and what gaps they might have to fill in order to move on.

We thought about how to promote that message to a population who is not used to project management. We decided we wanted this to be a Mars Bar. You know it looked good, it tasted good and my goodness it did you good. It had to deliver every time. So we had no shame in saying, this is a Brand, it is going to be established as a Brand leader and we had a clear strategy to promote it as a Brand from day one. The Brand documentation was purposely world class and is written in plain English which includes no unique project management speak. OGC know it is world class because people have stolen it all over the world. We had high-class multi media promotion to promote the brand because it was not going to promote itself fast enough. And like a Mars Bar, we controlled the quality. We determined the team members, what they did and how they acted. People do not turn up because they are good people. They turn up because they have passed the accreditation test for being allowed to turn up. And that was very important. Now did we win the brand battle? Yes we did. If you flick on the $\mathrm{BBC}$ website and listen to the transcripts for the BBC news, you will hear every month a Minister on the radio being asked something like, 'okay Minister, how do you know this particular defence project is going to work?'. And he will say, 'because I've been working it with OGC Gateway team and they tell me we're on the right track'. Now that is Brand success. Each Minister has been given one of the Gateway brand management check lists and there's about 40,000 copies of these have been used. That is what comes of five years of branding. And people now know the term. The Prime Minister will use the term on radio. Ministers will use it. And they actually will understand what they are talking about too, which is even better.

\section{Establishing Brand Criteria}

In order to control the quality of this Mars bar, we had to decide on the quality elements. For us it was free at the point of delivery and then meeting the criteria shown in the slide. Because if you have a brand it is important to say how would 
you recognise it if you fell over it in the street. There are two issues to particularly emphasise (Fig 2). One is independence and the next is an accredited practitioner team. Who turns up is vital, and they are very distinguished people for the big projects. It will be somebody from the Sydney Olympics who does the Gate Zero review of the London Olympics. They have been there before, they are not scared of big decisions and have learnt from their mistakes. These are very impressive people and they are tuned to the projects size and complexity. The teams who turn up will have been there before and will recognise what is going on in minutes. And that is what is impressive. Next, fast delivery-five days maximum for a review, including writing the report. Even for an aircraft carrier project this is doable. It assumes it is an $80 / 20$ process. It is very important to note that an OGC Gateway Review is not an audit and it is not quality assurance - it is an $80 / 20$ top down management process, massively well received as a result of it being a short and focused review. The last thing to mention on criteria is access to stakeholders. That means all stakeholders. If it is a ministerial priority the Minister will be interviewed, they usually want to be interviewed but, if for some reason they are not available, we just simply will not do the review rather than fail to understand the issues. Good advice would be to stick to the elements that matter in the Branding.

\title{
Figure 2
}

\section{Key Elements of the OGC Gateway Brand}

\author{
- Project Lifecycle assessed versus best practice \\ - Independent and accredited practitioner team \\ - Short focused Review \\ - Open, plain English process \\ - Access to all stakeholders \\ - Candid recommendations \\ - Ownerships of follow-through rests with client \\ - Confidential client - team partnership
}

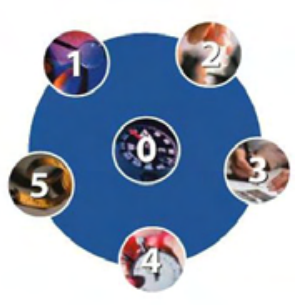


You can only get away with all of these process of course if it is based on reality. So it is a fact that the real successes have helped us preserve our position today. The sort of repeat issues that come up at each of these six gate reviews are shown in Figure 3. We know eight or nine things that, if we could stop them going wrong on every project, life would be more successful. At each Gateway review we are limited to ten or twelve points only that the team will be examining. What they will do is rapidly home down on three or four. Typically some of these repeat points, such as leadership, business case, adequate skills and resources will be amongst them. That's fairly normal and enables OGC to focus project help.

\title{
Figure 3
}

\section{NAO \& OGC Gateway'm Review - Key Lessons}

\author{
Essentials for Programme/Project Success include: \\ - Robust Business Case (with pre- \\ agreed Critical Success Factors) \\ - Adequate skills and resources \\ - Ongoing risk management process \\ - Clearly defined roles \& \\ responsibilities \\ - Effective stakeholder communication
}

\section{Mission Critical Projects}

The UK had a problem to solve. We were producing 6.5 per cent improvement rates on our project portfolio. That actually hid the fact that for the small projects (50 to 100 million-dollar projects) we were achieving 20 per cent improvement. For the very largest ones, the ones that were nearest the heart of political change, we were only achieving 3-4 per cent. So we did a study to find out why and then more importantly try to decide what to do about it. Figure 4 shows the results of our study and of Gartners worldwide study of what goes wrong with the very largest government projects. Not everyone may agree with it. 
Figure 4

Causes of Failure in Highest Risk Programs

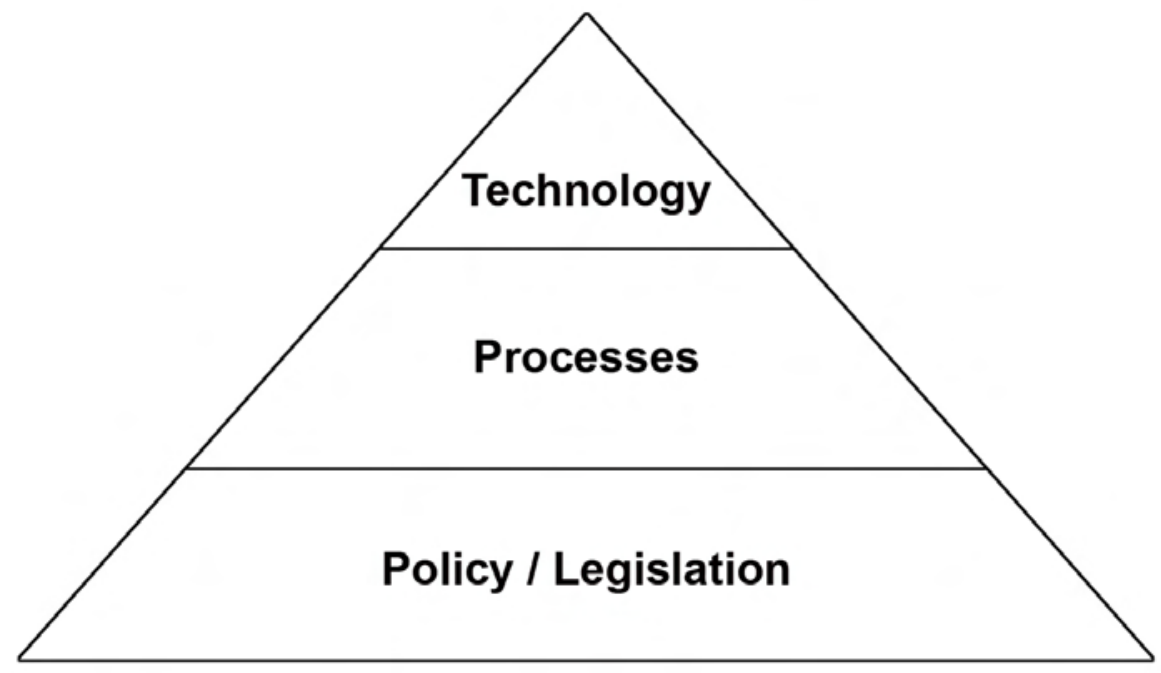

What it suggests is that technology is not the problem on the very largest projects. Project management processes are not the problem on the very largest projects, but the clarity of policy interpretation, the scope of it and understanding the political intention is the crunch that causes the very largest to either succeed or fail. OGC realised that we were not putting enough effort into the early stages of policy development and policy deliverability. And so we are moving on to getting involved with the policy developers before it even becomes a policy. What we did on the London Olympics, was to be involved with our project management teams as the bid was produced. So there were no excuses for the bid not to be right. We worked out a program where all the Ministers and Permanent Secretaries got involved and identified their key success indicators, which varied widely. Then we pulled them together and fed that back to the ministers as a group. The better news is we have also set up for the first time ever, a cross-functional ministerial group with a role in running the Olympic program. There are six Cabinet Ministers chaired by an independent Cabinet Minister who run the Olympic program. Please note the word 'run', they are not there as a safety valve, they have a job to do in setting priorities, and resolving escalated problems. So that is a real success. And we're now going to bring that success into all of our cross-functional projects. So what we now do is before the Gateway review program even starts we run an activity with the project at the stage of policy development. It can be done but only because of who turns up to help and their credibility in crossing the divide between project 
management and policy. The sort of people who do that, some retired Chief Executives of FTSE 100 companies, some ex-Permanent Secretaries in the UK, are all distinguished people who have been around and carry the credibility to talk to policy makers and are independently minded.

\section{Conclusions}

The Gateway program itself is now internationally trademarked to protect its integrity. So if it is not a Mars Bar it is a Coca Cola. You know it arrives tasting good, at the right temperature and it arrives in the same shape all of the time. And like Coca Cola, OGC do not distribute the products unless we are quite sure they are in good hands. There is more to do, since there is an ever-growing need to keep building capability at very senior levels. The policy makers and the politicians have shown great enthusiasm and patience in being involved with this Gateway process and they want to continue to be involved.

The UK Cabinet Secretary, Sir Andrew Turnbull gave the nicest accolade the Gateway program has had. He said, 'The OGC Gateway program is one of those more rare initiatives that has permanently changed Government'. 